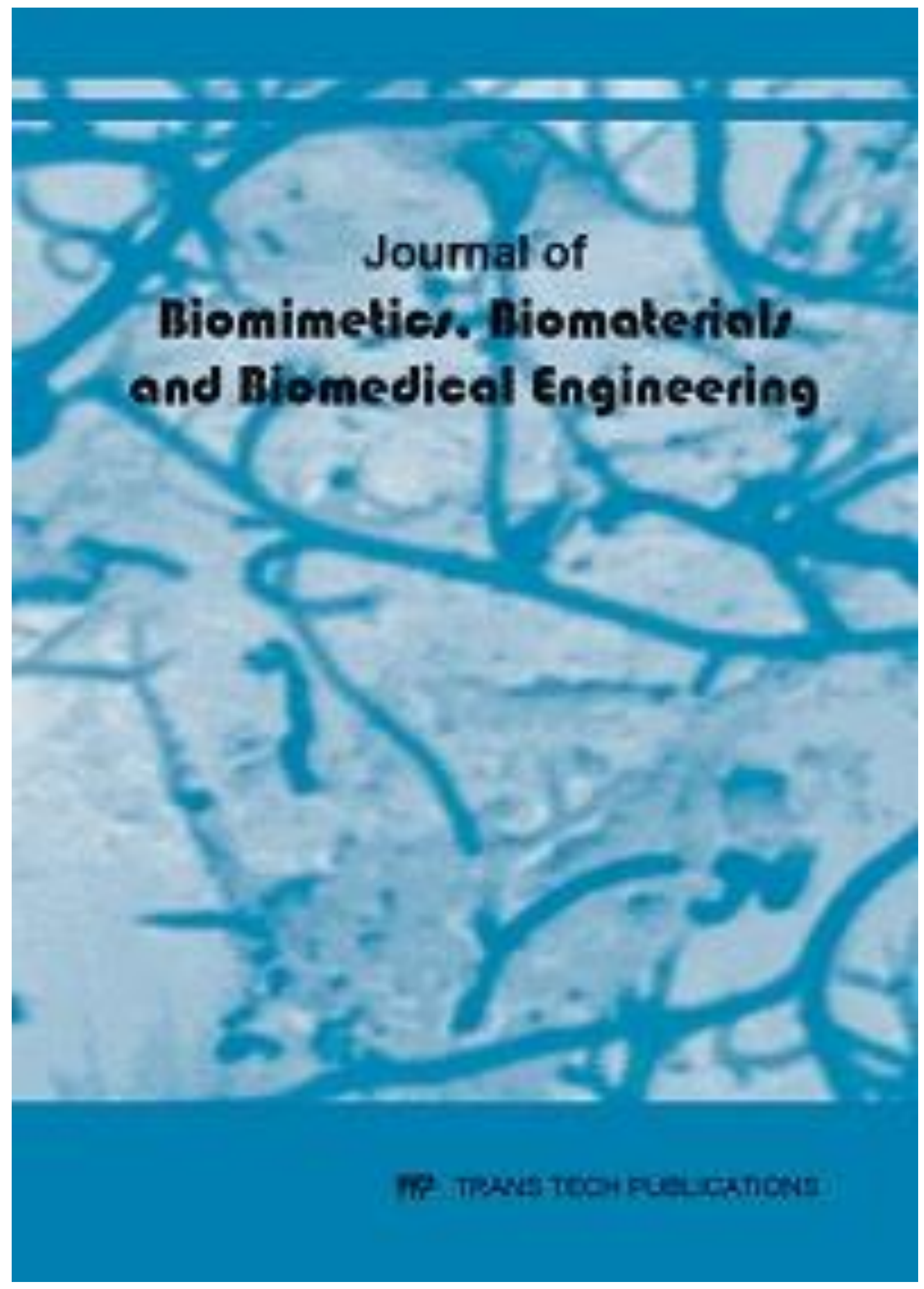




\section{Periodicals}

\section{Journal of Biomimetics, Biomaterials and Biomedical Engineering ISSN: 2296-9845}

Volumes (/JBBBE)

My eBooks (/JBBBE/ebooks)

Details (/JBBBE/Details)

Editorial Board (/JBBBE/Editors)

Editor(s) in Chief

\section{Dr. Sooraj Hussain Nandyala}

ORCID (https://orcid.org/0000-0002-2736-5224).

Universidade do Porto, Departamento de Física, Faculdade de Ciências; Rua do Campo Alegre 687, Porto, 4169-007, Portugal;

Senior Editors

\section{Dr. Stanislav Kolisnychenko}

\section{Editorial Board}

\section{Mr. Souvik Das}

SHEIKHPARA A. R. M. POLYTECHNIC, GOVT. OF WEST BENGAL, MEDICAL LABORATORY TECHNOLOGY; Sheikhpara, Murshidabad, Nadia, India, 741235;

\section{Prof. Qing Ling Feng}

Tsinghua University, School of Materials Science and Engineering; Beijing, China, 100084;

\section{Dr. Yao Dong Gu}

Ningbo University; No.818, Fenghua Road, Ningbo, China, 315211;

\section{Prof. Mohammad Abu Jafar Mazumder}

King Fahd University of Petroleum and Minerals, Chemistry Department; P. O. Box \# 1683, Dhahran, Saudi Arabia, 31261;

\section{Dr. Krishna Madhavan}

University of Colorado at Denver, Health Sciences Center; Denver, USA; 


\section{Prof. F.N. Oktar}

Marmara University, Department of Bioengineering, Faculty of Engineering; Goztepe Campus, Engineering D Building, Kuyubasi, 34722, Turkey;

\section{Prof. Murugan Ramalingam}

Centre for Stem Cell Research (a Unit of inStem, Bengaluru), Christian Medical College and Hospital Campus; Bagayam, India, 632002;

\section{Prof. Débora dos Santos Tavares}

Federal University of Sergipe, Health Campus, Education in Health Department, Colégio Estadual Prof. Abelardo Romero Dantas; Rua Padre Alvares Pitangueira, n. 248., Centro Lagarto - SE, Brazil, 49.400-000;

\section{GET ACCESS (/ACCOUNT/SUBSCRIPTIONS)}

SYSTEM GUIDE (/INFO)

DISTRIBUTORS (/DISTRIBUTOR)

SUPPLEMENTS (/SUPPLEMENTS)

ABOUT US (/HOME/ABOUTUS)

POLICY \& ETHICS (/HOME/MISCONDUCT)

CONTACT US (/HOME/CONTACTS)

IMPRINT \& PRIVACY POLICY (/HOME/IMPRINTANDPRIVACYPOLICY)

SITEMAP (/HOME/SITEMAP) 


\section{Main Themes}

\section{Journal of Biomimetics, Biomaterials and Biomedical Engineering Vol. 38}

Volume 38

doi: https://doi.org/10.4028/www.scientific.net/JBBBE.38

(https://doi.org/10.4028/www.scientific.net/JBBBE.38)

Papers (/JBBBE.38)

Book (JJBBBE.38/book)

\section{Search}

Biomechanical Performance of Habitually Barefoot and Shod Runners

during Barefoot Jogging and Running_(J JBBBE.38.1)

Authors: Suo Di Xu, Zhi Qiang Liang, Yu Wei Liu, Gusztáv Fekete

Abstract: The purpose of this study was to evaluate the biomechanical

performances, running stability of habitually barefoot (BR) and shod runners (SR)

...more

Prediction of Creep Strain Relaxations in Biomaterials Using

Differential Transformation Method (JJBBBE.38.11).

Authors: Olurotimi Adeleye, Augustine Eloka, Gbeminiyi Sobamowo

Abstract: The outcome of most implant failures is tragic. There is an increasing need to reduce the rate of implant failure. While there has been a lot of progress

...more

Local and Global Statistical Data on Malaria Images (JJBBBE.38.23)

Authors: Siti Nurul Aqmariah Mohd Kanafiah, Mohd Yusoff Mashor, Wan Azani Mustafa, Zeehaida Mohamed, Shazmin Aniza Abdul Shukor, Haniza Yazid, Z.R.

Yahya 
Abstract: Malaria appears to be one of the main reasons for detrimental health issue at the global scale that is responsible for approximately half a million deaths ...more

Examination of Biodegradable Magnesium Screw Processed by Equal

Channel Angular Pressing: A Novel In Vivo Study in Rabbits

\section{(IJBBBE.38.31)}

Authors: Ista Damayanti, Benny Syariefsyah Latief, Abdul Latif, Bambang

Pontjo Priosoeryanto, Sugeng Supriadi, Fourier Dzar Eljabbar Latief

Abstract: Magnesium alloys have shown potential as biodegradable metallic

materials for oral and maxillofacial surgery applications due to their degradability. ...more

Silicocarnotite Synthesis and Bioactivity in Artificial Saliva Medium

(IJBBBE.38.38).

Authors: Adil Bouregba, Adeljebbar Diouri

Abstract: The aim of this study is the synthesis and investigation of bioactive response of acrystalline silicophosphate.A monophasic silicocarnotite was

...more

Characterization of Cassava Fibre for Potential Wound Dressing

Application (JJBBBE.38.47)

Authors: Stanley Dickson Kushigbor, Bernard Elorm Adem, Sarah Ofori Wadieh, Grace Kwaku-Anim, Michael Frimpong Danso, Godwin Amenorpe, Elsie Effah Kaufmann

Abstract: Wound dressing is the application of a sterile pad to protect a wound from further harm and promote healing. Over the past decades, various materials ...more

In Vitro Comparative Study of Osteogenic Differentiation Ability. between Adipose and Bone Marrow Mesenchymal Stem Cell Applied to Bovine Demineralized Bone Matrix (/JBBBE.38.59).

Authors: Ferdiansyah Mahyudin, Dwikora Novembri Utomo, Mouli Edward, Lukas Widhiyanto, Christopher Anthony Simanjuntak, Hudaya Nikmatullah Abstract: Ideal bone graft must possess the desirable trait such as osteoconductive, osteoinductive and osteogenesis. Demineralized Bone Matrix ...more

Rapid Protocol of Porcine Kidney Decellularization (/JBBBE.38.67)

Authors: Fernanda Rocha de Souza, Maria Aparecida Dalboni, Andreas Kaasi, José Osmar Medina de Abreu Pestana, Adalberto Ramón Vieyra, Nádia Karina Guimarães de Souza

Abstract: Chronic kidney disease is a problem that has grown in recent decades worldwide. The National Kidney Foundation (NKF) estimates that the number of ...more 


\title{
In Vitro Comparative Study of Osteogenic Differentiation Ability between Adipose and Bone Marrow Mesenchymal Stem Cell Applied to Bovine Demineralized Bone Matrix
}

\author{
Ferdiansyah Mahyudin ${ }^{1, a, *}$, Dwikora Novembri Utomo ${ }^{1, b}$, Mouli Edward ${ }^{1, \mathrm{c}}$, \\ Lukas Widhiyanto $^{1, \mathrm{~d}}$, Christopher Anthony Simanjuntak ${ }^{1, \mathrm{e}}$, \\ Hudaya Nikmatullah ${ }^{1, f}$
}

\begin{abstract}
${ }^{1}$ Department of Orthopedic and Traumatology, Faculty of Medicine, Universitas Airlangga/Dr. Soetomo General Hospital, Indonesia

aferdyortho@gmail.com, bdwikora-novembri-u@fk.unair.ac.id, 'mouli-edward@fk.unair.ac.id, dlukas-w@fk.unair.ac.id, ${ }^{\mathrm{e}}$ cas.orthosby@gmail.com, 'hudaya.nikmatullah@gmail.com
\end{abstract}

*Corresponding author: ferdyortho@gmail.com

Keywords: bone defect, demineralized bone matrix, mesenchymal stem cell

\begin{abstract}
Ideal bone graft must possess the desirable trait such as osteoconductive, osteoinductive and osteogenesis. Demineralized Bone Matrix (DBM) provides both osteoconductive and osteoinductive trait. Referring to the tissue engineering principle, the addition of mesenchymal stem cell would add the osteogenic trait to this procedure. The design of this study is experimental using Bovine DBM. Bone Marrow Mesenchymal Stem Cell (BMSCs) and Adipose Mesenchymal Stem Cells (ASCs) were taken from New Zealand white rabbit. There are two groups of treatment, divided into DBM implanted with BMSCs and DBM implanted with ASCs. Each BMSCs and ASCs groups is incubated in the normal and osteogenic culture plate. Evaluation is performed by counting the osteoblast and immunohistochemistry stain using Alkaline Phosphate and Osteocalcin. After 4 weeks of incubation, we found that the osteoblast count in BMSCs groups is higher compared to the ASCs groups in both culture condition $(\mathrm{p}<0.01)$ along with Alkaline Phosphate staining $(p<0.05)$, while the Osteocalcin staining showed insignificant differences $(p>0.05)$. This study revealed that xenogenic bovine DBM can act as the potential osteoinductive scaffold for the MSCs to differentiate. The tissue engineering application by combining MSCs and Bovine DBM can be considered as an alternative in managing bone defect cases.
\end{abstract}

\section{Introduction}

Bone defects are one of the major problems in orthopedic cases. It can occur in both trauma and non trauma cases. In bone defects, discontinuities of bone integrity can be caused by high-energy trauma, infection, tumor resection surgery, revision surgery, developmental deformities, and congenital malformation disorders. In this case, the size of the bone defect is too large and is included in the critically sized defect so it will not undergo spontaneous regeneration and require an interventional operation [1,2]. There are 500,000 surgeries that require bone grafting in the United States within a year with a total cost of 300 million USD in 1999 [3]. For comparison, the use of bone graft for orthopedic surgery at Dr. Soetomo General Hospital Surabaya has quadrupled from 1997 to 2001 [4]. Bone defect treatment requires the bone graft to fill the gap and autologous bone graft is still a gold standard in the treatment of bone defect cases [5]. However, postoperative pain in bone donor source areas is of concern in the use of autologous bone graft besides its limitations of the bone sources [6]. Other alternatives for the graft subtitutes are allogenic bone graft and animals xenogenic bone graft. Allograft is physiologically more resembling the original bone and may have osteoinductive properties but the donor availability is also limited and disease transmission still be concerned. Whereas xenograft, owing to the abundance of donors, may be less expensive and more readily available even though its properties are limited to osteoconductive alone [7]. 
With the rapid progress in the concept of tissue engineering, the use of stem cells that originally are exogenous cells in bone tissue engineering serves osteogenic capacity in stimulating bone healing [8,9]. Together with the development of scaffolding techniques by performing demineralization so cellular components that potentially induce immune response can be eliminated, thus providing potential scaffold as a microenvironment of the stem cell [8].

Considering this, bovine Demineralized Bone Matrix (DBM) which is a xenogenic bone graft product can be rated as the alternative bone graft substitues, because its osteoconductive and osteoinductive properties can serve as a scaffold to support stem cell proliferation and differentiation thus provide osteogenic capacity [9]. Besides its economically cost, bovine DBM has been shown to have higher bone healing promotion capacities than the other type of bone graft and has lower immunogenicity and rejection reactions to surrounding tissue [10]. This current study will test and compare the ability of bovine DBM as scaffold and growth factor provider to stimulate differentiation of bone marrow and adipose mesenchymal stem cells to enhance its function as a bone graft.

\section{Materials and Methods}

This study was an in vitro laboratory study conducted at the Institute of Tropical Disease (ITD) Airlangga University and Tissue Bank of Dr. Soetomo General Hospital in Surabaya, Indonesia. The experimental unit was BMSCs and ASCs isolated from a healthy male New Zealand white rabbit 8 months old and weighing $3.0 \mathrm{~kg}$ approved by Airlangga University and Dr. Soetomo General Hospital research committee. In this study, bovine DBM added to isolated and replicated BMSCs and ASCs and divided into 4 groups (Figure 1).

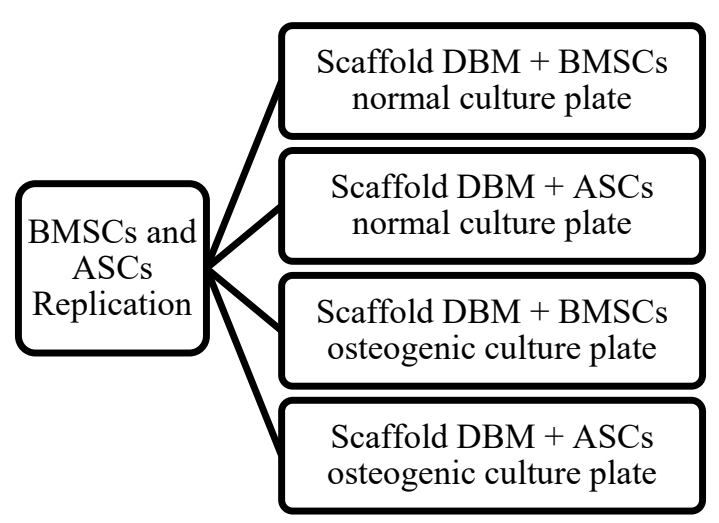

Figure 1. Research design

\subsection{Preparation of bovine demineralized bone matrix}

Demineralized bone matrix, prepared from the femoral condyle of the 2-year-old local cow, were collected from the local slaughterhouse. All bones were collected aseptically, and the soft tissues were removed before storage at $-70^{\circ} \mathrm{C}$. The bones were later cleared of fascia and cut into $1-\mathrm{cm}$ pieces with a bone saw under saline $(0.9 \% \mathrm{NaCl})$ solution lavage. Bone pieces were stored at $-70^{\circ} \mathrm{C}$ until further use. The pieces were then thawed in 95\% ethanol for 15 minutes and air dried. All bones were milled to $10 \mathrm{~mm}$ pieces. The pieces were then decalcified in $0.6 \mathrm{~mol} / 1 \mathrm{HCl}$ at $4^{\circ} \mathrm{C}$ for 8 days under constant agitation. After demineralization, all bone pieces were rinsed in sterile water and placed in phosphate buffer overnight. The bone pieces were then rinsed and the $\mathrm{pH}$ was adjusted to 7.3. They were placed in ethanol, the ethanol was allowed to evaporate overnight, and the pieces were packaged aseptically and stored at $4^{\circ} \mathrm{C}$.

\subsection{Isolation of bone marrow mesenchymal stem cells}

Animals were anesthetized with ketamine (40 mg/kg, IM) and xylazine (5 mg/kg, IM). Isolation of MSCs from bone marrow performed aseptically by cleaning the skin of rabbit femur. The muscle and connective tissue were removed from the femur by scraping the diaphysis of the bone clean 
then pulling the tissue toward the ends of the bone. A 27-gauge needle was inserted and flushed with Dulbecco's Modified Eagle's Medium (DMEM) and collect in a $15 \mathrm{~mL}$ tube. The cell suspension was filtered through a $70-\mu \mathrm{m}$ filter mesh. Bone marrow cells were cultured in $\mathrm{DMEM}+10 \% \mathrm{FBS}+1 \%$ antibiotic-antimycotic solution tissue culture flask and incubated at $37^{\circ} \mathrm{C}$ with $5 \% \mathrm{CO}_{2}$. For osteogenic culture, $10 \mathrm{mmol}$ dexamethasone, $10 \mathrm{mmol} \beta$-glycerol-phosphate, $0.05 \mathrm{mmol} 2$-phosphate ascorbic acid, $100 \mathrm{U} / \mathrm{mL}$ penicillin/streptomycin, and $10 \mathrm{mmol} 1,25-$ dihydroxy vitamin D3 were added to culture plate.

\subsection{Isolation of adipose mesenchymal stem cells}

Isolation of MSCs from adipose tissue was performed by subcutaneous fat pad liposuction under sterile conditions and washed with phosphate-buffered saline (PBS) containing 1\% antibioticantimycotic solution. The washing step was repeated until all blood vessels and connective tissues appeared to have been liberated. Adipose tissue then minced into small pieces and digested in $0.1 \%$ type 1 collagenase at $37^{\circ} \mathrm{C}$ with shaking for 2 hours and added $5 \mathrm{~mL}$ DMEM containing $10 \%$ fetal bovine serum. For further disintegration of tissue aggregates, the sample was pipetted up and down several times. The cell suspension was filtered through $100 \mu \mathrm{m}$ filter for the removal of the solid aggregates. The sample was subsequently centrifuged at $2000 \mathrm{rpm}$ for 5 minutes at room temperature to complete the separation of the stromal cells from the adipocytes and the supernatant removed without disturbing the cells. The pellet was resuspended in $1 \mathrm{ml}$ of lysis buffer to lyse red blood cells, incubated for 10 minutes, washed with $10 \mathrm{ml}$ of PBS $+1 \%$ antibiotic-antimycotic mixture and centrifuged at $2000 \mathrm{rpm}$ for 5 minutes. The supernatant was removed and the cell pellet was resuspended in complete medium (DMEM with 20\% fetal bovine serum (FBS) and 1\% antibiotic-antimycotic solution) in a $25 \mathrm{~cm}^{2}$ culture flask and maintained in an incubator supplied with the humidified atmosphere of $5 \% \mathrm{CO}_{2}$ at $37^{\circ} \mathrm{C}$.

\subsection{Cell cultivation}

After one day, non-adherent cells were removed by two to three washes with PBS and adherent cells further cultured in complete medium. The medium was changed every 3 days until the monolayer of adherent cells reached $70-80 \%$ confluence. Cell passaging was performed using trypsin-EDTA solution $0.25 \%$. Cell cultivation was performed up to the $3^{\text {rd }}$ passage.

\subsection{Osteogenic differentiation}

Passage 3 MSCs were harvested by trypsin digestion as described above. The cells were counted and seeded at a density of $5 \times 10^{4}$ per well in a 9-well plate each group. The medium was changed twice per week for 2-3 weeks. The differentiation potential for osteogenesis was observed by the number of osteoblasts, alkaline phosphatase (ALP), and osteocalcin (OC). The number of osteoblasts assessed by hematoxylin-eosin staining, osteogenic marker gene of alkaline phosphatase and osteocalcin assessed by immunohistochemical staining under immunofluorescence microscopy. The Immunoreactive Score (IRS) by Remmele is a scale index is used to quantify the immunohistochemistry findings resulted by multiplication of immunoreactive cell percentage scores with color intensity scores on immunoreactive cells (Table 1). The data of each microscopic examinations were observed in 5 fields of view.

Table 1. The semi-quantitative scale of the IRS (IRS result $=\mathrm{AxB})$

\begin{tabular}{l|l}
\hline \multicolumn{1}{c|}{ A } & \multicolumn{1}{c}{ B } \\
\hline Score 0: no positive cells & Score 0: no color reactions \\
Score 1: positive cells less than $10 \%$ & Score 1: low color intensity \\
Score 2: positive cells ranging from $11 \%-50 \%$ & Score 2: medium color intensity \\
Score 3: positive cells between from $51 \%-80 \%$ & Score 3: strong color intensity \\
Score 4: positive cells between from more than $80 \%$ & \\
\hline
\end{tabular}




\section{Results and Discussion}

The MSCs cultures were observed by using an inverted light microscope. Adherence of spindleshaped cells to culture plastic flask was observed after 1 day of culture for both BMSCs and ASCs. Primary cultures reached 70-80\% confluence faster in BMSCs than for ASCs (Figure 2).
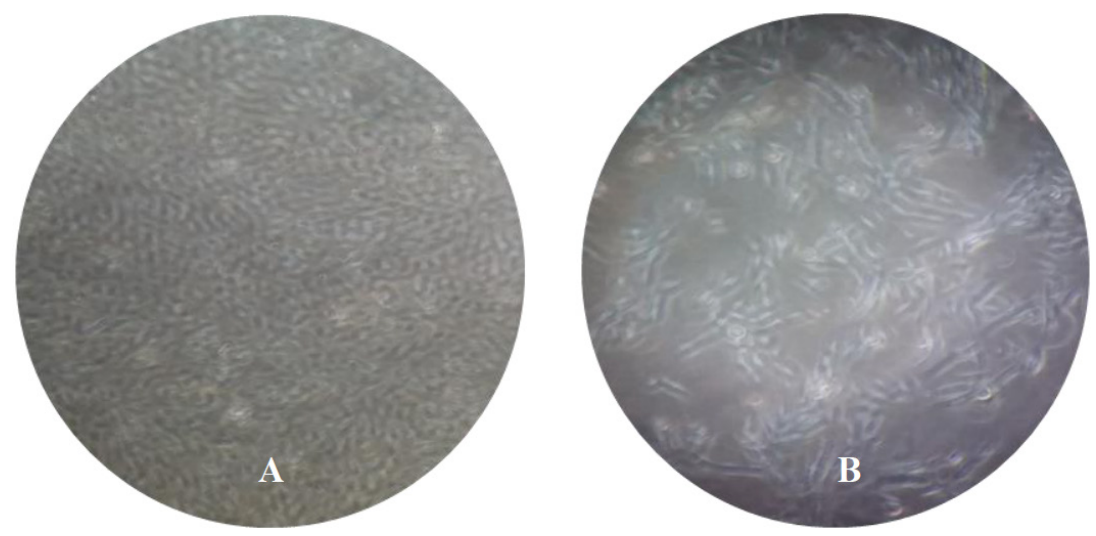

Figure 2. (A) Bone marrow stem cells culture, (B) Adipose stem cells culture

Table 2 and Figure 3 reveal the mean total number of osteoblast cells in the BMSCs group added with bovine DBM and cultured at normal condition was $7.67 \pm 2.00$ cells per 5 fields of view, higher than the osteoblast cell number in the ASCs group $(1.44 \pm 1.24)$ and the difference is statistically significant $(p=0.000)$. Similiar significant result found for the mean of osteoblast number cells in the osteogenic culture, BMSCs group was 120.67 \pm 28.54 compared to ASCs group $73.00 \pm 42.32$ cells number per 5 fields of view $(p=0.013)$.

Table 2. Osteogenic differentiation of mesenchymal stem cells

\begin{tabular}{lcccc}
\hline & \multicolumn{2}{c}{$\begin{array}{c}\text { BMSCs } \\
\text { (Mean } \pm \text { SD) }\end{array}$} & \multicolumn{2}{c}{$\begin{array}{c}\text { ASCs } \\
\text { (Mean } \pm \text { SD) }\end{array}$} \\
\cline { 2 - 5 } & \multicolumn{4}{c}{ Culture Condition } \\
\hline & Normal & Osteogenic & Normal & Osteogenic \\
Osteoblast Count (Cell number/ 5 FV) & $7.67 \pm 2.00$ & $120.67 \pm 28.54$ & $1.44 \pm 1.24$ & $73.00 \pm 42.32$ \\
ALP Expression (IRS Score) & $3.20 \pm 0.63$ & $3.84 \pm 0.53$ & $1.12 \pm 0.36$ & $1.16 \pm 0.33$ \\
Osteocalcin Expression (IRS Score) & $1.96 \pm 0.59$ & $3.16 \pm 0.45$ & $2.18 \pm 0.75$ & $3.29 \pm 0.61$ \\
\hline
\end{tabular}

The average immunoreactive score (IRS) of ALP expression in BMSCs group added with bovine DBM within normal culture was $3.20 \pm 0.63$ compared to $1.12 \pm 0.36$ in ASCs groups and had a statistically significant effect $(p=0.000)$. Thus in osteogenic culture, the IRS mean of the ALP expression in the BMSCs group compared to ASCs group added with bovine DBM also differ significantly $(\mathrm{p}=0,000)$.
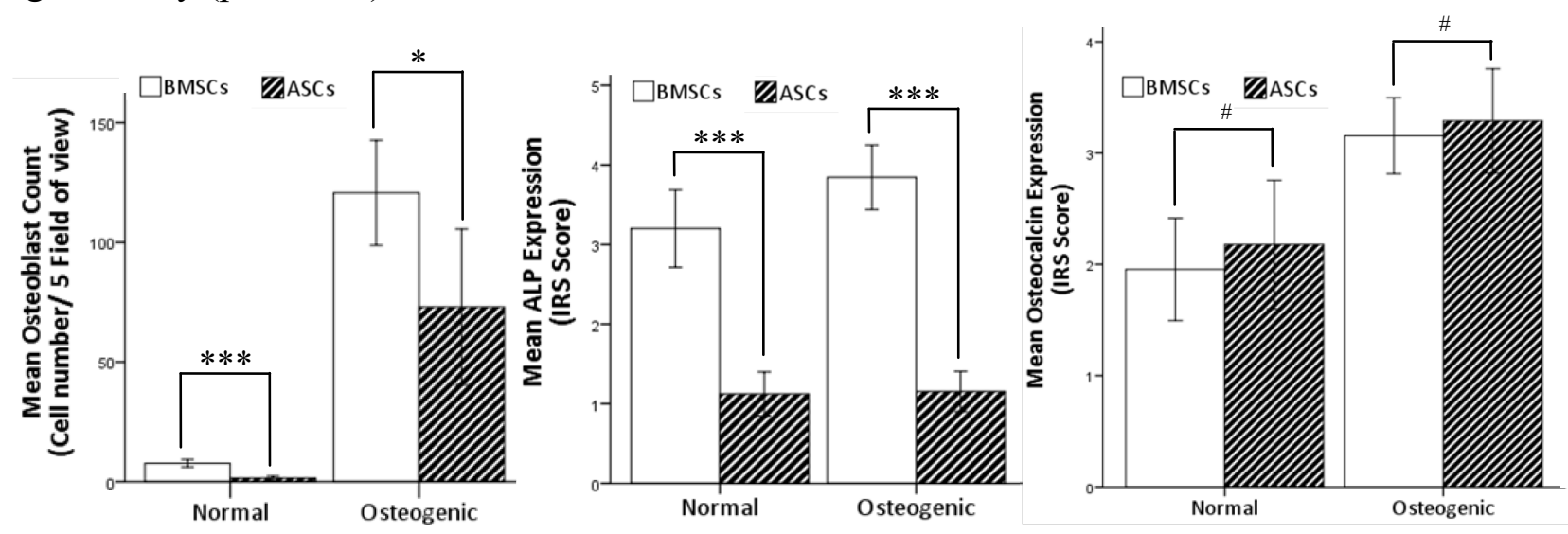

Culture Condition

Figure 3. Number of osteoblast cell, immunoreactive score of ALP and osteocalcin for BMSCs and ASCs within normal and osteogenic culture, $\left(*=\mathrm{p}<0.05^{* *}=\mathrm{p}<0.01 * * * \mathrm{p}<0.001{ }^{\#}=\mathrm{p}>0.05\right)$ 
The mean immunoreactive score of OC expression in the BMSCs group added with bovine DBM and cultured at normal condition was slightly lower than in the ASCs group (1.96 $\pm 0.59 v s$ $2.18 \pm 0.75)$ but not statistically significant $(\mathrm{p}=0.498)$. Whereas the average IRS of osteocalcin expression at osteogenic culture in BMSCs group was 3.16 \pm 0.45 and 3.29 \pm 0.61 in ASCs group but the results were not statistically significant $(\mathrm{p}=0.603)$.
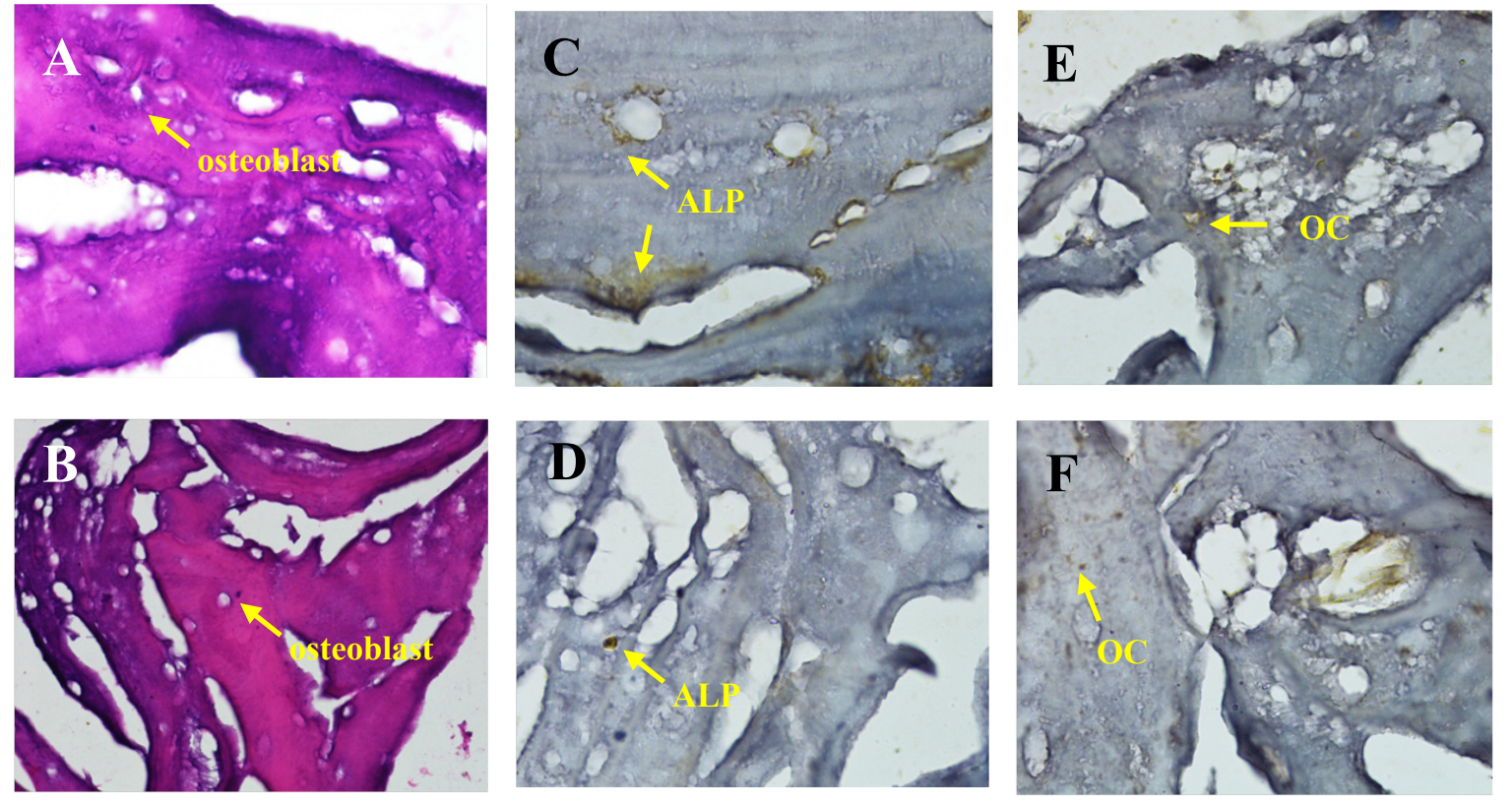

Figure 4. (A) HE staining on normal culture of BMSCs, (B) HE staining on normal culture of ASCs, (C) ALP expression in normal culture of BMSCs, (D) ALP expression in normal culture ASCs tissue, (E) OC expression in normal culture of BMSCs tissue, (F) OC expression result in normal culture ASCs tissue.
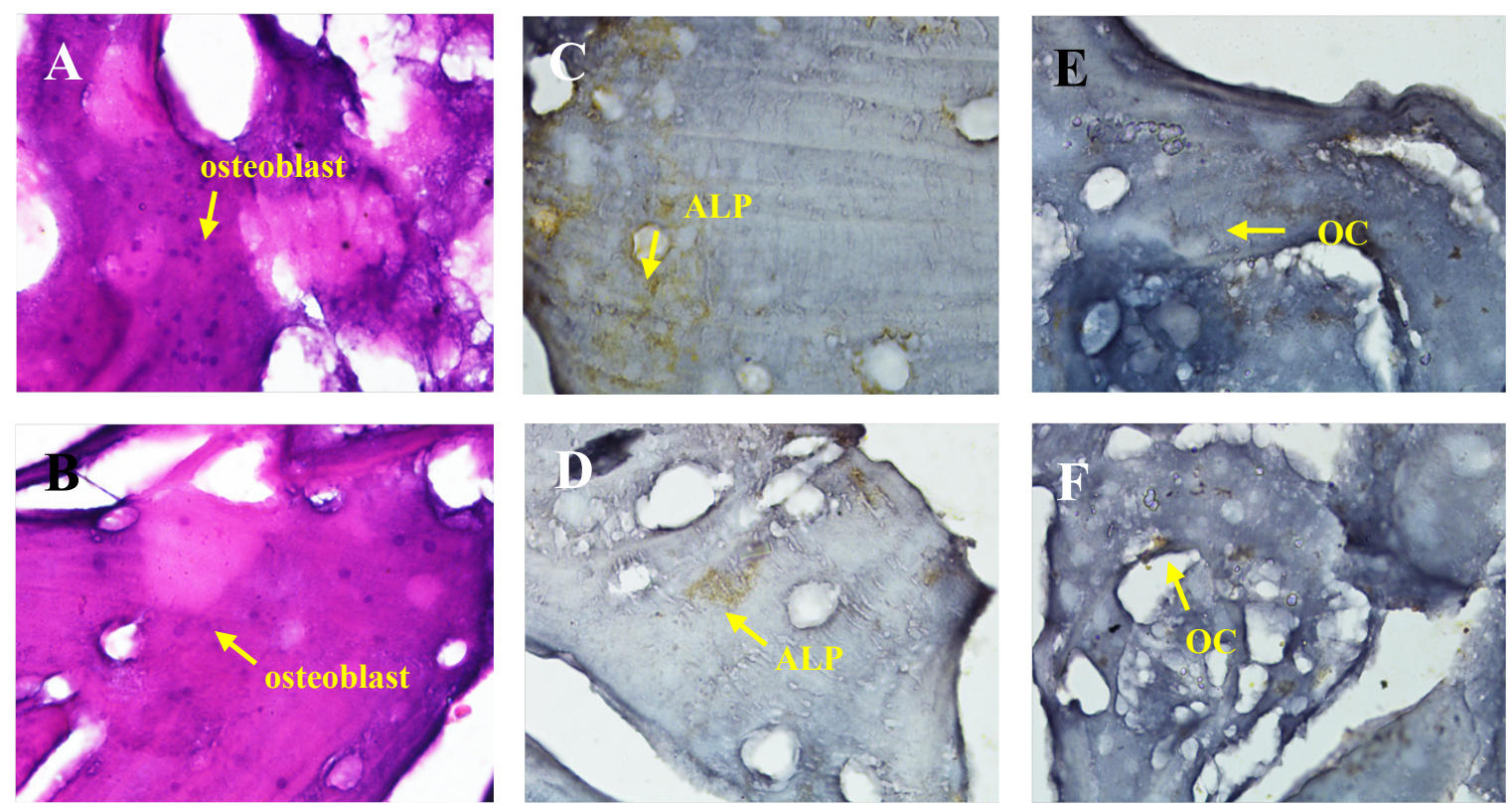

Figure 5. (A) HE staining on osteogenic culture of BMSCs. (B) HE Staining on osteogenic culture of ASCs (C) ALP expression in osteogenic culture of BMSCs, (D) ALP expression in osteogenic culture ASCs tissue, (E) OC expression in osteogenic culture of BMSCs, (F) OC expression result in osteogenic culture ASCs.

The use of stem cells in combination with scaffolds showed mixed results. The capability of mesenchymal stem cell differentiation (MSC) largely determines its use in managing various tissue damage. Stem cells derived from bone marrow are MSCs which was first studied and used widely. However, the morbidity induced when taking BMSCs causes other sources such as adipose and umbilical cord mesenchymal stem cells is further investigated [11]. Although most researchers conclude that BMSCs have better osteogenic proliferation capabilities than others [12-14], Kern et 
al investigated the differentiation of bone marrow, adipose, and umbilical cord mesenchymal stem cells, became bone, and the results showed no significant difference between BMSCs and ASCs [15]. This led to the study using both types of stem cells growing at a rapid rate to handle orthopedic cases with bone defects.

Studies by Garmie et al and Janicki et al showed promising results from stem cell and scaffold applications of non-connective fractures [16,17]. However, this study supported by several other studies, shows that BMSCs remain superior to muscle, adipose and umbilical cord [18-20]. Other studies have suggested the use of embryonic stem cells with scaffolds with promising results, but limited cell resources and difficulty in processing require further study to obtain optimal results [21]. Liu et al used ASCs inserted into the scaffold of the shells to correct the cranial defects in experimental animals with satisfactory results [22].

Several experiments have been conducted to combine DBM with MSC. Schubert et al reported a significant difference between the use of ASCs implanted into DBM compared with the autopsy of the cancellous bones in spinal fusion using pig experiments [23]. Evaluations performed using CT scans and histologic examinations showed better performance in the group DBM added A-MSCs. Several other researchers have tried to combine DBM with BMSCs with satisfactory results [24,25].

The results of this study indicate a significant comparison in which the amount of osteoblasts and alkaline phosphatase expression produced by differentiation of BMSCs is higher than ASCs, but the resulting osteocalcin expression did not differ significantly. This is in line with the previous hypothesis that BMSCs have a higher osteogenic differentiation potential than ASCs. This study also proves that bovine DBM is able to function as a scaffold where stem cells differentiate into osteoblasts.

Studies using ASCs and the scaffold, both DBM and other scaffold forms, are still widely used to determine their efficacy in overcoming bone defects, as the use of BMSCs means increasing morbidity in patients in the form of pain in bone marrow collection sites. The authors argue that in vivo research is needed to directly compare the efficacy of DBM use in the treatment of bone defects in addition to ASCs or BMSCs.

\section{Conclusion}

Xenogenic bovine Demineralized Bone Matrix (DBM) is able to function as a scaffold where mesenchymal stem cells differentiate into osteoblast cells. Bone marrow mesenchymal stem cells have better osteogenic differentiation capabilities than adipose mesenchymal stem cells when implanted into Demineralized Bone Matrix.

\section{References}

[1]Arun R. S., Michael C. M., Jeffrey O. H. Bone Tissue Engineering: State of the Union. Drug Discovery Today, 2014;19:781-786. https://doi.org/10.1016/j.drudis.2014.04.010

[2]Natasha H., Matthew B. Focus on Management of Traumatic Bone Loss. Journal of Bone and Joint Surgery, 2011.

[3]Greenwald AS, Boden SD, Goldberg VM, et al, 2002. Bone Graf Substitute: Facts, Fictions \& Applications. Committee on Biological Implants. American Academy of Orthopaedic Surgeons. 69th Annual Meeting. Dallas, Texas.

[4]Abdurrahman, 2002. Indonesian Tissue Banking: Progress on Tissue Production and Development of Quality Assurance, the 9th International Conference on Tissue Bank. Seoul.

[5]Calori GM, Mazza E, Colombo M, Ripamonti C. The use of bone-graft substitutes in large bone defects: any specific needs? Injury, 2011 Sep;42 Suppl 2: S56-63.

[6]Lementowski P.W. 2010. Acute and Chronic Complications of Intracortical Iliac Crest Bone Grafting Versus the Traditional Corticocancellous Technique for Spinal Fusion Surgery. Orthopedics, April 2010,33(4). https://doi.org/10.3928/01477447-20100225-08 
[7]Shibuya N1, Jupiter DC2Bone graft substitute: allograft and xenograft. Clin Podiatr Med Surg, 2015 Jan;32(1):21-34. https://doi.org/10.1016/j.cpm.2014.09.011

[8]Sean M. Devitt et al. Successful Isolation of Viable Adipose-derived Stem Cells from Human Adipose Tissue Subject to Long-Term Cryopreservation: Positive Implications for Adult Stem Cell-Based Therapeutics in Patient of Advanced Age. Stem Cells International, 2015. https://dx.doi.org/10.1155/2015/146421

[9]Sarvazyan, N. Cell and Tissue Engineering. Creation of Living Tissue: An Engineering Feat. Springer-Verlag Berlin Heidelberg. 2012, 1(8): 1-8.

[10] Mahyudin F, Utomo DN, Suroto H, Wahyu T, Edward M, Gaol IL. Comparative Effectiveness of Bone Grafting using Xenograft Freeze-Dried Cortical Bovine, Allograft Freeze-Dried Cortical New Zealand White Rabbit, Xenograft Hydroxyapatite Bovine, and Xenograft Demineralized Bone Matrix Bovine in Bone Defect of Femoral. 2017;2017:1-11. https://doi.org/10.1155/2017/7571523

[11] Arrington ED, Smith WJ, Chambers HG, et al. Complications of iliac crest bone graft harvesting. Clin Orthop Relat Res 1996;(329):300-9.

[12] Bajada S, Mazakova I, Richardson JB, et al. Updates on stem cells and their applications in regenerative medicine. J Tissue Eng Regen Med 2008;2:169-83.

https://doi.org/10.1002/term.83

[13]Bianco P, Riminucci M, Gronthos S, et al. Bone marrow stromal stem cells: nature, biology, and potential applications. Stem Cells, 2001;19:180-92. https://doi.org/10.1634/stemcells.19-3180

[14] Niemeyer P, Kornacker M, Mehlhorn A, et al. Comparison of immunological properties of bone marrow stromal cells and adipose tissue-derived stem cells before and after osteogenic differentiation in vitro. Tissue Eng, 2007;13(1):111-21. https://doi.org/10.1089/ten.2006.0114

[15] Kern, $\mathrm{S}$ et al. Comparative analysis of mesenchymal stem cells from bone marrow, umbilical cord blood, or adipose tissue. Stem Cells, 2006;24(5):1294-1301.

https://doi.org/10.1634/stemcells.2005-0342

[16] Gamie, $Z$ et al. Stem cells combined with bone graft substitutes in skeletal tissue engineering. Expert Opin Biol Ther, 2012;12(6):713-729. https://doi.org/10.1517/14712598.2012.679652

[17] Janicki P, Schmidmaier G. What should be the characteristics of the ideal bone graft substitute? Combining scaffolds with growth factors and/or stem cells. Injury 2011;42:S77-81. https://doi.org/10.1016/j.injury.2011.06.014

[18] Yoshimura H, Muneta T, Nimura A, et al. Comparison of rat mesenchymal stem cells derived from bone marrow, synovium, periosteum, adipose tissue, and muscle. Cell Tissue Res, 2007; 327: 449-62. https://doi.org/10.1007/s00441-006-0308-z

[19] Schneider RK, Puellen A, Kramann R, et al. The osteogenic differentiation of adult bone marrow and perinatal umbilical mesenchymal stem cells and matrix remodeling in threedimensional collagen scaffolds. Biomaterials, 2010;31:467-80. https://doi.org/ 10.1016/j.biomaterials.2009.09.059

[20] Ohgushi H, Dohi Y, Tamai S, et al. Osteogenic differentiation of marrow stromal stem cells in porous hydroxyapatite ceramics. J Biomed Mater Res, 1993;27:1401-7.

[21]Levenberg S, Huang NF, Lavik E, et al. Differentiation of human embryonic stem cells on three-dimensional polymer scaffolds. Proc Natl Acad Sci USA, 2003;100:12741-6. https://doi.org/10.1073/pnas. 1735463100 
[22] Liu, $G$ et al. 2013. Bone regeneration in a canine cranial model using allogeneic adipose derived stem cells and coral scaffold. Biomaterials, 2013;34(11):2655-2664. https://doi.org/10.1016/j.biomaterials.2013.01.004

[23] Schubert, $T$ et al. 2013. Critical size bone defect reconstruction by an autologous 3D osteogenic-like tissue derived from differentiated adipose MSCs. Biomaterials, 2013;34:44284438 .

[24] Mauney JR, Jaquiery C, Volloch V, et al. In vitro and in vivo evaluation of differentially demineralized cancellous bone scaffolds combined with human bone marrow stromal cells for tissue engineering. Biomaterials, 2005;26:3173-85.

https://doi.org/10.1016/j.biomaterials.2004.08.020

[25] Liu G, Sun J, Li Y, et al. Evaluation of partially demineralized osteoporotic cancellous bone matrix combined with human bone marrow stromal cells for tissue engineering: an in vitro and in vivo study. Calcif Tissue Int, 2008;83:176-85. https://doi.org/ 10.1007/s00223-008-9159-9. 